\title{
Digital Product Innovation in Manufacturing Industries - Towards a Taxonomy for Feedback-driven Product Development Scenarios
}

\author{
Manuel Holler \\ University of St.Gallen, Institute \\ of Information Management \\ manuel.holler@unisg.ch
}

\author{
Gerard Neiditsch \\ University of St.Gallen, Institute \\ of Information Management \\ gerard.neiditsch@unisg.ch
}

\author{
Falk Uebernickel \\ University of St.Gallen, Institute \\ of Information Management \\ falk.uebernickel@unisg.ch
}

\author{
Walter Brenner \\ University of St.Gallen, Institute \\ of Information Management \\ walter.brenner@unisg.ch
}

\begin{abstract}
In the light of pervasive digitalization, traditional physical products get augmented with digital components that create the potential of making the whole product lifecycle visible for product developers. As numerous opportunities sketch out how feedback such as sensor data might be leveraged for future products, a comprehensive model to describe, particularly a classification model to organize and structure these opportunities seems analytically useful. Hence, this paper pursues a scenario-based approach and proposes a taxonomy for feedback-driven product development scenarios in manufacturing industries. Grounded on (1) empirical data from case studies and focus groups and (2) a systematic literature review, we follow an established taxonomy development method employing the general systems theory as meta-characteristic. With the limitation of a (1) qualitative, interpretive empirical research design and a (2) representative literature review, we contribute to the body of knowledge by shedding light on feedback-driven product development from a classification perspective which may act as structuring and creativity fostering tool.
\end{abstract}

\section{Introduction}

Managing the lifecycle of industrial products has been perceived as challenging issues in both academia and industry for several decades $[1,2,3]$. Within the setting of manufacturing, an established conceptualization of this product lifecycle is the division into beginning-of-life (BOL), middle-of-life (MOL), and end-of-life (EOL). Thereby, BOL encompasses product conceptualization, definition, and realization. MOL comprises product usage, service, and maintenance. EOL may be shaped by various pathways ranging from refurbishing to disposal $[2,3,4]$. From a chronological viewpoint, these phases are commonly not distributed equally. Dependent on the product type, the duration of the MOL phase can exceed the duration of the BOL phase by far $[2,3,4]$. On closer examination, industrial enterprises have very limited information about the actual usage of their products once they are sold to their customers $[2,4,5]$. Although it is widely acknowledged that information about product usage is highly beneficial for the development of future products [2,4,6,7], manufacturers scarcely get feedback from the field - with the exception of selective snapshots from customer service or even complaints from customers. Conditioned by lacking technological capabilities, product usage has received little attention from product development departments in the past.

However, in the light of pervasive digitalization, traditional physical products get augmented with digital components $[8,9,10]$ that create the potential of making the whole product lifecycle visible for product developers [2,4,7]. Traditional industrial products ranging from heavy engineer-to-order machinery to automotive make-to-stock-planning modules get infused with digital technologies such as sensors, networks, and processors [8,9,10]. Recent market research from strategy consultancy Oliver Wyman attempts to quantify this development and forecasts the number of connected objects across all industries to 75 billion in 2020 [11]. Hence, there may be billions of opportunities for product developers to obtain large-scale quantified and reliable insights from products in use.

Numerous opportunities sketch out how feedback such as sensor data might be leveraged for future products. A comprehensive model to describe, particularly a classification model to organize and structure these abundant and diverse opportunities seems analytically useful for product developers and decision makers discovering the benefits of digitized products. Yet, extant models are not capable of adequately describing the landscape of feedbackdriven product development. Hence, this paper pursues a scenario-based approach and builds a classification model. Therefore, we (1) draw upon empirically derived scenarios from case studies and focus groups in four distinct manufacturing industries and (2) classify these objects of interest in a taxonomy for feedback-driven product development scenarios, guided by the method proposed by Nickerson et al. [12]. Accordingly, we frame the guiding research question for this paper as follows: 
[RQ] "What are dimensions and characteristics that describe feedback-driven product development scenarios in manufacturing industries?"

The remainder of this paper is organized in the following way: In section 2, we provide an overview on the theoretical background, i.e. digital product innovation, product development, and related work. In section 3, the applied taxonomy development method with both empirical-to-conceptual and conceptual-to-empirical approach is introduced. In section 4 , we present the taxonomy and illustrate it by the aid of an exemplary scenario in section 5 . Finally, we conclude with a summary, implications for scholars and practitioners, and research limitations in section 6 .

\section{Theoretical background}

\subsection{Digital product innovation}

As result of the pervasive infiltration of information technology across all industries, the nature of innovation has changed significantly over the last decades [13], and manufacturing industries represent no exception. As a matter of principle, the impact of digital technologies on innovation may appear in two manifestations [13]. First, digital technologies may affect the innovation process. Second, digital technologies may influence the innovation process outcome [13]. In the former case, a digital tool, in the latter case, a digital component, acts as trigger or enabler [13].

Table 1. Selected concepts and conceptualizations related to "digitized products"

\begin{tabular}{|c|c|}
\hline Concept & Conceptualization \\
\hline $\begin{array}{l}\text { Digitized } \\
\text { products }\end{array}$ & $\begin{array}{l}\text { "(...) digitization makes physical products } \\
\text { programmable, addressable, sensible, communicable, } \\
\text { memorable, traceable, and associable }(\ldots) "[9: 725,10]\end{array}$ \\
\hline $\begin{array}{l}\text { Cyber- } \\
\text { physical } \\
\text { systems }\end{array}$ & $\begin{array}{l}\text { "(...) are integrations of computation with physical } \\
\text { processes. Embedded computers and networks } \\
\text { monitor and control the physical processes, usually } \\
\text { with feedback loops where physical processes affect } \\
\text { computations and vice versa }(\ldots) "[15: 1,16]\end{array}$ \\
\hline $\begin{array}{l}\text { Intelligent } \\
\text { products }\end{array}$ & $\begin{array}{l}\text { "(...) contain sensing, memory, data processing, } \\
\text { reasoning, and communication capabilities }(\ldots) " \\
{[4: 480,17]}\end{array}$ \\
\hline $\begin{array}{l}\text { Smart } \\
\text { objects }\end{array}$ & $\begin{array}{l}\text { "(...) possess a unique identity, are capable of } \\
\text { communicating effectively with their environment, } \\
\text { can retain data about themselves, deploy a language, } \\
\text { and are capable of making decisions }(\ldots) " \\
{[18: 284,19]}\end{array}$ \\
\hline $\begin{array}{l}\text { Smart, } \\
\text { connected } \\
\text { products }\end{array}$ & $\begin{array}{l}\text { "(...) consist of physical components, smart } \\
\text { components (sensors, microprocessors, data storage, } \\
\text { controls, software, operating system), and } \\
\text { connectivity components (ports, antenna, protocols) } \\
(\ldots) "[20: 67]\end{array}$ \\
\hline $\begin{array}{l}\text { Internet of } \\
\text { things }\end{array}$ & $\begin{array}{l}\text { "(..) everyday objects can be equipped with } \\
\text { identifying, sensing, networking, and processing } \\
\text { capabilities that will allow them to communicate with } \\
\text { one another and with other devices and services over } \\
\text { the Internet }(\ldots) \text { " }[21: 261,22]\end{array}$ \\
\hline
\end{tabular}

As this paper explores the role of digital components embedded in physical products, our research is positioned in the field of digital product innovation which must be diligently distinguished from digital process innovation [9]. Yoo et al. conceptualize digital product innovation as "carrying out of new combinations of digital and physical components to produce novel products" [9:725], which goes in line with the Schumpeterian perspective on innovation. These new combinations of digital and physical materiality [14] can be described by the layered-modular architecture (contents layer, service layer, network layer, and device layer) in a comprehensive way [9]. Table 1 provides a survey on selected concepts and conceptualizations related to "digitized products" rooted in different scientific domains. Honoring concepts from the engineering and computer science domain at this juncture and utilizing their contributions at a subsequent stage, this paper employs the nomenclature of digitized products as it is the most comprehensive, scholarly mature, and in information systems dominant concept [9], used by several authors [e.g.,23,24].

\subsection{Product development}

In a generic sense, product development describes the process of bringing new products to market $[25,26]$. From an historical viewpoint, product development was influenced by different research streams [1]. Understood entirely as research and development project in the 1960s, marketing, organization, strategy, and operations research served as dominant logic for product development over the next decades [1]. Since the 1990s, product development can be regarded as an IT-enabled innovation process [1]. Furthermore, product development encompasses a strong integrative aspect involving all relevant stakeholders [25,26]. According to a recent conceptualization by Eigner and Roubanov, "product development encompasses all activities and disciplines that describe the product and its production, operations, and disposal over the product lifecycle, engineering disciplines, and supply chain with the result of a comprehensive product definition" [27:7]. Thereby, product development can been regarded as an integral part of product lifecycle management - a strategy of managing a company's products across their lifecycles [2,3]. In the domain of information systems, product development is an emerging field $[1,13]$, "information systems can serve as reference discipline" [1:1]. Research on the relationship of digital product innovation and product development is still in its infancy. Yoo et al. [9] note two main implications: With embedded digital capabilities, products offer (1) novel functions and enhanced price/performance ratios that however (2) fundamentally transform development processes and challenge existing product architectures and organizing logics. 


\subsection{Related work}

Upon the interdisciplinary nature of the subject, related work can be found in various research domains. In a broader sense, the field of closed-loop product lifecycle management deals with seamless and multi-directional information flows through all lifecycle phases [4,28]. More specifically, regarding the information flow between individual lifecycle phases, several articles [e.g.,29,30] concentrate on narrow issues along the chain from identification, collection, storage, and analysis of product usage data. However, previous studies investigate the exploitation rather from maintenance points of view than from design perspectives [31,32]. Furthermore, the emerging field of big data $\&$ analytics [e.g.,33,34] seems qualified to provide valuable contributions, which increasingly discusses issues related to product lifecycle management [35]. Beyond, in the domain of computer science, the field feedback-driven software engineering [e.g.,36] is nascent. In the narrower sense, certain classification models related to digital product innovation exist. For example, Herterich et al. [37] developed a taxonomy for service systems enabled by digital product innovation. With a taxonomic framework for context aware computing for the Internet of things, Perera et al. [38] provide another example. However, these taxonomies have different purposes and foci than product development. Herterich et al. [37] address industrial service systems with the theory of affordances as lens, Perera et al. [38] take a strong technical perspective and neglect business benefits. Up to the authors' knowledge, there exists no research to describe feedback-driven product development from a classification perspective. In the following, we address this gap with a scenario-based, taxonomic approach.

\section{Research methodology}

\subsection{Methodological foundations}

According to March and Smith, "a model can be viewed simply as a description, that is, as a representation of how things are" [39:256], which is the purpose of our research endeavor. Wellestablished models to help scholars and practitioners understand and analyze complex domains are classification models which class objects of interest $[12,40,41]$. As the classification of objects is a fundamental task in various research domains, several paradigms, terminologies, and development methods exist. Going back to foundational literature on classification $[42,43,44]$, extant studies distinguish - beside more general notions such as classification or framework - particularly typologies (theoretically derived) and taxonomies (empirically derived).
For this paper, we employ the method proposed by Nickerson et al. [12] by several reasons. First, it integrates inductive and deductive techniques. Second, it is well-accepted in the information systems domain where we position our research in and strive to contribute to. Finally, this approach is situated in the field of design science research $[45,46]$ with the main goal to create a new useful artifact. Following Nickerson et al. [12], we define a taxonomy as a set of dimensions each consisting of mutually exclusive and collectively exhaustive characteristics such that each object of interest has exactly one characteristic for each dimension. In the case at hand, the objects of interest are scenarios which represent narrative descriptions of activity sequences [47,48]. We selected a scenario-based approach as "scenarios are ideal for exploring and defining the behavior of systems involving people in complex business procedures" [49:21]. Scenariobased research endeavors on product development have been realized successfully [50]. In line with Carroll $[47,48]$, our understanding of a scenario is a specific, qualitative description how data from the MOL stage ("product usage") may be leveraged for BOL purposes ("product development") to enhance future products. For the taxonomy, scenarios were derived from (1) case studies and focus groups and (2) complemented by extant work.

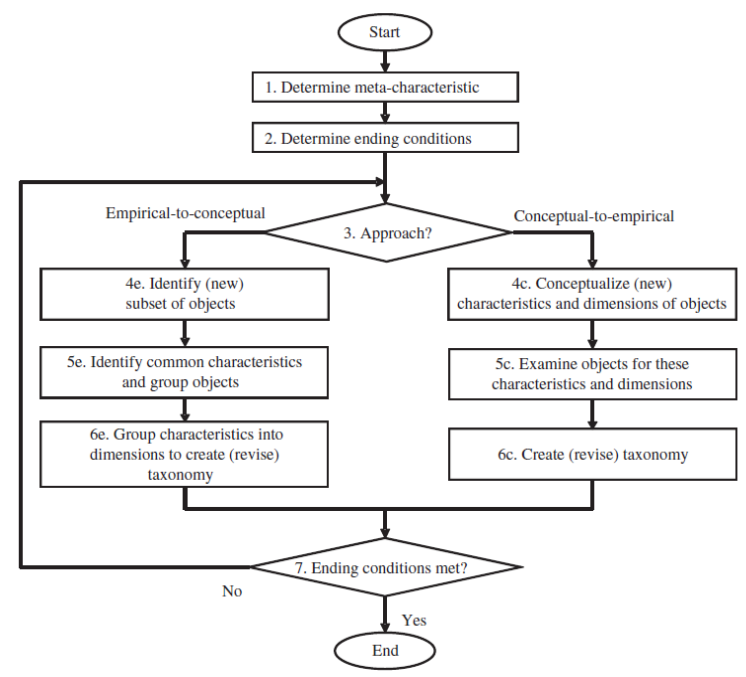

Figure 1. Method for taxonomy development in information systems by Nickerson et al. [12]

Figure 1 illustrates this method for taxonomy development in information systems. As Nickerson et al. [12] emphasize the relevance of taxonomies on the one hand, but identify methodological weaknesses on the other hand, we pursue a rigorous and transparent approach. Initially, we diligently selected the metacharacteristic which represents most comprehensive characteristic of the taxonomy [12]. In line with the proposed purpose ("a tool to foster transparency and 
creativity") and the proposed users ("product developers and decision makers in traditional manufacturing industries discovering the benefits of digitized products"), we grounded our metacharacteristic in the general systems theory. The general systems theory is the "transdisciplinary study of the abstract organization of phenomena, independent of their substance, type, or spatial or temporal scale of existence" [51:2]. Thereby, the concept "system" plays an essential role which can be characterized by (1) emergent properties, (2) layered structure, and (3) processes of communication and control [52]. We consider product development as a system with those characteristics. Product developers and decision makers need to be informed which system inputs they have to process in which way, and what may be potential system outputs. Subsequently, we defined objective and subjective ending conditions. A fundamental objective ending condition is that the taxonomy consists of dimensions each with mutually exclusive and collectively exhaustive characteristics [12]. Beyond, we included subjective ending conditions: Our final taxonomy should be concise, robust, comprehensive, explanatory, extendible, and comprehensive [12]. In the empirical-to-conceptual approach, dimensions and characteristics are derived inductively from the objects as logical sequence of the meta-characteristic [12]. In contrast, in the conceptual-to-empirical approach, dimensions and characteristics are developed without the objects and then synchronized [12]. The taxonomy development process is iterative until all imposed ending conditions are met.

\subsection{Empirical-to-conceptual approach}

For the empirical-to-conceptual approach, we applied case study research following Yin [53] and Eisenhardt [54], complemented by focus groups following Morgan [55]. A case study represents an "empirical inquiry that investigates a contemporary phenomenon within its real-life context, especially when the boundaries between phenomenon and context are not clearly evident" [53:13], which seems an appropriate research method in consideration of our research endeavor. With qualitative research, we targeted to (1) identify scenarios for a subsequent classification and (2) explore potential dimensions and characteristics that may describe feedback-driven product development.

Guided by our research question, we selected a purposeful case sampling strategy [56,57]. First, to ensure comparison, maximize variation, and obtain rich, diverse insights, we considered the spectrum of manufacturing industries ranging from engineer-toorder through to make-to-stock-planning enterprises [58] (maximum variation sampling [57]). Second, we took typical manufacturing companies into account which have recognized the potential of digitized products (typical case sampling [57]). Table 2 provides an overview on the involved case organizations and sources of evidence. Case organization MachineCorp (revenue $<1,000 \mathrm{MN} €$ ) is a special engineering company manufacturing special machinery for luxuries. Case organization ForkLift (revenue >2,001 $\mathrm{MN} €$ ) is a materials handling original equipment manufacturer (OEM) developing trucks of high quality and durability. Case organization CarSupply (revenue 1,001-2,000 MN €) is a first tier automotive supplier providing mechatronic chassis systems to automotive OEMs. Case organization INGeneering (revenue >30,001 $\mathrm{MN} €)$ is one the largest diversified industrial consortia in Europe which unites various business areas under its roof.

Table 2. Overview on case organizations and sources of evidence

\begin{tabular}{|c|c|}
\hline Case organ. & Sources of evidence \\
\hline $\begin{array}{l}\text { MachineCorp } \\
\text { (Special } \\
\text { engineering) }\end{array}$ & $\begin{array}{l}\text { Semi-structured interviews } \\
\text { [A] Head of engineering design } \\
\text { [B] Head of control engineering } \\
\text { [C] Project lead control engineering } \\
\text { [D] Head of manufacturing engineering } \\
\text { [E] Head of technical IT }\end{array}$ \\
\hline $\begin{array}{l}\text { ForkLift } \\
\text { (Materials } \\
\text { handling } \\
(\text { OEM)) }\end{array}$ & $\begin{array}{l}\text { Semi-structured interviews } \\
{[\mathrm{F}] \text { Project lead strategic product platforms }} \\
{[\mathrm{G}] \text { Project lead advance development }} \\
{[\mathrm{H}] \text { Project lead advance development }} \\
\text { [I] Senior engineer advance development } \\
{[\mathrm{J}] \text { Head of product lifecycle management }} \\
{[\mathrm{K}] \text { Head of master data management }}\end{array}$ \\
\hline $\begin{array}{l}\text { CarSupply } \\
\text { (Automotive } \\
\text { (first tier } \\
\text { supplier)) }\end{array}$ & $\begin{array}{l}\text { Semi-structured interviews } \\
{[\mathrm{L}] \text { Head of innovation and technology }} \\
\text { [M] Senior engineer product design } \\
\text { [N] Senior engineer product simulation } \\
\text { [O] Chief information officer }\end{array}$ \\
\hline $\begin{array}{l}\text { INGeneering } \\
\text { (Diversified } \\
\text { industrial } \\
\text { consortium) }\end{array}$ & $\begin{array}{l}\text { Focus groups } \\
\text { Digitalization forum with focus on digitized } \\
\text { industrial equipment: Eight focus group } \\
\text { workshops with both technology- and } \\
\text { management-oriented executives }\end{array}$ \\
\hline
\end{tabular}

With the purpose to collect potential scenarios that can be classified in a taxonomy, semi-structured interviews [53,54] acted as main source of evidence. For the interviewee sampling, we applied (purposeful) theoretical sampling $[56,57]$ to approximate our study objectives in an iterative way rather than executing a pre-built scheme. In a first step, we interviewed informants with a broad overview. In the subsequent steps, with the goal to learn more about the discovered issues, we identified additional, more specialized informants. This "snowball approach" was applied until additional data resulted in only minimal new information and scenarios became repetitive. Accordingly, interviewees came from a variety of relevant functions (e.g., product design, product simulation) and different ranks (e.g., head of engineering design, project lead advance development). The interviews were realized from June 2015 to January 2016 with 
two guiding elements. First, a questionnaire was developed along recommendations by Schultze and Avital [59] which encompassed the following sections: Introduction, interviewee's and company's background, trends in product development, strategies, processes, and information systems related to feedback-driven product development, scenario identification, and conclusion. Second, we employed paper-based scenario templates to support the scenario identification. Thereby, the scenario templates $[47,48,49]$ were organized as follows: Scenarios are identified by a number and a short title. Involved stakeholders and a standard process can be described. The main section of the scenario template is structured along the system input-processingoutput framework. Lastly, the scenario template encompasses space for comments and sources. First, we supplied the interviewees with exemplary scenarios from literature and asked to ideate similar applications in their own business environment. Interviews (minimum: 33 minutes, average: 64 minutes, maximum: 95 minutes) were recorded, anonymized, transcribed, and analyzed with computer-assisted qualitative data analysis software NVIVO 10 [60,61].

Furthermore, we had the opportunity to collect evidence from a digitalization forum at INGeneering with focus on digitized industrial equipment in the style of focus groups [55,62]. In eight workshop sessions (introduction, participants' and company's background, exemplary scenario presentation, individual ideation, group discussion, results presentation, and conclusion) of 90 minutes each in June 2015 with technology- and managementoriented executives, scenarios were identified. After the data collection, populated scenario templates were transferred in digital form and collected in a scenario database.

\subsection{Conceptual-to-empirical approach}

For the conceptual-to-empirical approach, we performed a systematic literature review following the established approach by vom Brocke et al. [63]. Furthermore, we enriched our review with methodological contributions from additional sources $[64,65]$. With the review, we aimed to (1) get an overview on related work, (2) identify existing scenarios, and (3) explore potential dimensions and characteristics for the taxonomy.

Referring to Cooper's framework [64], we position our review as follows: We focus on research outcomes. Our goal is the identification of central issues. The review results are presented neutrally. The coverage has representative character. We target to inform general scholars and practitioners. Upon the interdisciplinary and distributed nature of the review subject, the conceptualization of the topic was challenging. Hence, after a pre-screening of standard references a visual concept map with synonyms, superordinate, infraordinate, and related terms to involve all facets of the topic was developed. With the purpose to include high-quality contributions, we searched peer-reviewed journals and conferences through major scholarly databases. We aim to ground our taxonomy in extant work which we find in information systems, engineering, and management literature. For the key word search we applied the search string "(“product development" OR "product engineering") AND ("usage" OR "operational" OR "middle-of-life" OR "lifecycle" OR "feedback" OR "closed-loop") AND ("data" OR "information")" in the publication title and key words to go beyond domain-specific nomenclature and to focus on the actual phenomenon under investigation. To target the most current contributions, a fifteen year time frame from April 2001 to April 2016 was taken into consideration. Table 3 demonstrates the literature search and results (*publication title search only to reduce database search results $<1,000$ items).

Table 3. Literature search and results

\begin{tabular}{|c|c|c|}
\hline Database & Results & Net hits \\
\hline AIS Electronic Library & 0 & 0 \\
\hline EBSCOhost & 11 & 3 \\
\hline Emerald & 3 & 1 \\
\hline PAIS Index & 65 & 13 \\
\hline Science Direct* & 579 & 12 \\
\hline Web of Science* & 9 & 4 \\
\hline $\begin{array}{c}\text { Interim results (database search, } \\
\text { inclusion/exclusion) }\end{array}$ & 667 & 33 \\
\hline $\begin{array}{c}\text { Final results (duplicates, inclusion//exclusion, } \\
\text { forward/backward, recommendations) }\end{array}$ & 61 \\
\hline
\end{tabular}

The key word search amounted to 667 articles which were examined in a three-step approach reading title, abstract, and full text. In line with the review purpose, inclusion/exclusion criteria we elaborated: Articles are included if the publication (1) contains a scenario or (2) has a potential dimension and characteristics. Furthermore, we conducted a forward/backward search process (21 additional articles) and included recommendations by senior scholars and skilled practitioners (7 additional articles). Finally, the total count of publications for in-depth investigation resulted in 61 papers. Utilizing the standardized templates, existing scenarios were extracted from the papers and gathered in the case study database with overlapping and duplicate scenarios removed. The scenario identification from both case studies and focus groups and literature review resulted in 20 concrete, independent, and industry-overarching feedback-driven product development scenarios. In addition, these papers provided potential frameworks to anchor the taxonomy dimensions in the body of knowledge. 


\subsection{Taxonomy development and evaluation}

With regard to the development process, we strictly followed Nickerson's example for mobile applications in graphical, tabular form [12]. Considering the introduced methodological foundations, scenarios were initially partitioned in manageable subsets. We decided to use the empirical-to-conceptual approach first because we have several objects of interest available. Grounded on a first subset, we identified initial dimensions and characteristics relating to the meta-characteristic. For the next iteration, we decided to use the conceptualto-empirical approach in order to occupy another perspective. Also inspired by frameworks from literature, we conceptualized suitable dimensions and characteristics referring to the meta-characteristic and identified instances (scenarios). Both approaches were continued and alternated with subsequent examination of ending conditions after each iteration. Dependent on the fit, dimensions were added or removed and characteristics merged, split, or complemented until ending conditions were fulfilled. Six iterations were conducted. From an inductive viewpoint, source and method triangulation resulting in a substantial, saturated set of scenarios made a contribution towards collectively exhaustive characteristics. From a deductive viewpoint, anchoring characteristics in spanning frameworks from literature made a contribution towards collectively exhaustive characteristics. Specificity of scenarios and iterative modification of characteristics contributed towards mutual exclusivity.

With regard to evaluation strategies, Sonnenberg and vom Brocke [66] propose to conduct the artifact evaluation throughout the whole process. Upon the nature of our artifact, we selected the observational method case study [45] as suitable and studied it in an appropriate business environment with the evaluation technique of expert interviews [66]. The interviews were conducted with product developers and decision makers from the case organization MachineCorp, ForkLift, and CarSupply with two professionals each continuously during the design science research activities. During EVAL1, the problem statement and research gap was discussed. Subsequently, during EVAL2, questions referring to the design specifications and the selected methodology were asked. Finally, during EVAL3, the current version of the designed artifact was evaluated in an artificial setting. Thereby, audio was recorded and analyzed. Overall, participants appreciated the addressed problem, the selected scenarios-based model building approach, and the current version of the taxonomy. However, minor issues were addressed: First, we eliminated several dimensions and focused instead on those that are specific for the case of product development. Second, we emphasized the outcome dimension as interviewees were especially interested in potential applications of the feedback. In sum, the build-evaluate-pattern [66] enabled us to refine and sharpen our taxonomy.

\section{Results}

In the empirical-to-conceptual approach and the conceptual-to-empirical approach, a taxonomy for feedback-driven product development scenarios in manufacturing industries was developed. Table 4 illustrates the taxonomy. In line with the selected meta-characteristic, D1 to D3 refer to input, D4 to D5 refer to processing, and D6 to D9 refer to output dimensions. In the following, each dimension and characteristics including sources are elucidated.

D1 - Approach to data collection: During the case studies and literature review [28,29,30], it became evident that product developers can approach the feedback collection in two fundamental ways (D1). The reactive approach (C1.1) aims to collect errors of existing products which already occurred and strives to eliminate those failures for future products in a retrospective manner. In contrast, the proactive approach (C1.2) rather pursues a large-scale data collection and targets to avoid possible dissatisfactions by predicting the presumable product usage with subsequent tailored product design. Existing approaches in the special engineering, materials handling, and automotive supply business rather work ex post through qualitative, interpretive customer (service) feedback. With the dissemination of digitized products, increasingly quantified ex post and ex ante approaches become feasible.

D2 - Product data source (level of abstraction): With feedback from the field as essential precondition, D2 relates to the product data source in terms of level of abstraction to measure the scope of collected feedback. This fundamental dimension emerged from the scenarios as well as extant literature [29,30]. In this dimension, the characteristics product instance $(\mathrm{C} 2.1)$ and product class (C2.2) were identified. A product instance refers to a single product item whereas a product class contains several product items with the same or similar properties [29,30]. Whereas in the case of similar product usage (e.g., standardized automotive applications) it may be reasonable to gather feedback solely from representative product classes, it may be necessary to include all product instances of the installed base in other cases (e.g., highly individual engineer-to-order context).

D3 - Product data source (format of appearance): In line with existing studies [29,30], scenario identification and discussion with experts demonstrated the necessity of another dimension to describe the product data source in terms of format of appearance (D3). 


\begin{tabular}{|c|c|c|c|c|c|c|c|c|}
\hline & Dimension & \multicolumn{7}{|l|}{ Characteristics } \\
\hline \multirow{3}{*}{$\underline{\underline{\Xi}}$} & $\begin{array}{l}\text { D1 - Approach to data } \\
\text { collection }\end{array}$ & \multicolumn{4}{|c|}{ C1.1 - Reactive approach (ex post) } & \multicolumn{3}{|c|}{ C1.2 - Proactive approach (ex ante) } \\
\hline & $\begin{array}{l}\text { D2 - Product data source } \\
\text { (level of abstraction) }\end{array}$ & \multicolumn{4}{|l|}{ C2.1 - Product instance } & \multicolumn{3}{|c|}{ C2.2 - Product class } \\
\hline & $\begin{array}{l}\text { D3 - Product data source } \\
\text { (format of appearance) }\end{array}$ & \multicolumn{2}{|l|}{ C3.1 - Structured data } & \multicolumn{4}{|c|}{ C3.2 - Semi-structured data } & C3.3 - Unstructured data \\
\hline \multirow{2}{*}{ 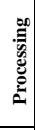 } & $\begin{array}{l}\text { D4 - Complexity of } \\
\text { feedback processing }\end{array}$ & \multicolumn{2}{|l|}{ C4.1 - Low complexity } & \multicolumn{4}{|c|}{ C4.2 - Medium complexity } & C4.3 - High complexity \\
\hline & $\begin{array}{l}\text { D5 - Degree of feedback } \\
\text { processing autonomy }\end{array}$ & \multicolumn{2}{|c|}{ C5.1 - Manual feedback processing } & \multicolumn{4}{|c|}{$\begin{array}{l}\text { C5.2 - Partially automated } \\
\text { feedback processing }\end{array}$} & $\begin{array}{l}\text { C5.3 - Automated feedback } \\
\text { processing }\end{array}$ \\
\hline \multirow{4}{*}{ 言 } & $\begin{array}{l}\text { D6 - Degree of product } \\
\text { novelty }\end{array}$ & \multicolumn{4}{|c|}{ C6.1 - New product development } & \multicolumn{3}{|c|}{ C6.2 - Product improvement } \\
\hline & $\begin{array}{l}\text { D7 - Addressed product } \\
\text { development stage }\end{array}$ & \multicolumn{2}{|c|}{ C7.1 - Product conceptualization } & \multicolumn{3}{|c|}{ C7.2 - Product definition } & & C7.3 - Product realization \\
\hline & $\begin{array}{l}\text { D8 - Enabled business } \\
\text { benefit }\end{array}$ & $\begin{array}{l}\text { C8.1 - Specification of } \\
\text { requirements }\end{array}$ & \multicolumn{3}{|c|}{$\begin{array}{l}\text { C8.2 - Customer-centric } \\
\text { product portfolio planning }\end{array}$} & \multicolumn{2}{|c|}{$\begin{array}{l}\text { C8.3 - Design for } \\
\text { usage }\end{array}$} & $\begin{array}{l}\text { C8.4 - Shortening of } \\
\text { physical prototyping }\end{array}$ \\
\hline & $\begin{array}{l}\text { D9 - Enabled increase in } \\
\text { value (neutral) }\end{array}$ & C9.1 - Technical & \multicolumn{2}{|c|}{ C9.2 - Economic } & $\begin{array}{l}\text { C9.3 - } \\
\text { Environm }\end{array}$ & & C9.4-So & $\begin{array}{l}\text { C9.5 - } \\
\text { Combinations }\end{array}$ \\
\hline
\end{tabular}

Table 4. Towards a taxonomy for feedback-driven product development scenarios

In this dimension, the format of appearance structured data (C3.1), semi-structured data (C3.2), and unstructured data (C3.3) may be distinguished. Whereas structured data typically encompass measures or meta-data such as sensor data, unstructured data usually consist of text, pictures, audio, and video [29,30]. In most scenarios, interviewees drew on structured measures such as sensor data in all variant forms (e.g., mechanical, kinematic, thermal, and fluid), but also saw potentials for value-adding insights from unstructured data in some scenarios.

D4 - Complexity of feedback processing: Identified scenarios were described by a wide spectrum of feedback acquisition, modeling, reasoning, and distribution techniques as classified in [38]. Hence, D4 summarizes this complexity of feedback processing. From very basic procedures (e.g., tracking of operating hours) (C4.1) to complex data analyses (e.g., naturalistic driving studies) (C4.3), identified scenarios exhibited strongly diverse processing complexity. It is the purpose to demonstrate the importance of this dimension in the context of feedback-driven product development, rather than to present technical details which are not specific and can be found in existing work [38].

D5 - Degree of feedback processing autonomy: Various working modes of integrating the feedback into the product development activities are conceivable. Indicated by the case studies and grounded in extant work [7], D5 describes the degree of feedback processing autonomy. Feedback can be incorporated completely manually (C5.1), partially automated (C5.2), or completely automated (C5.3). Although manually accomplished activities by the design and simulation engineers clearly outweigh in most empirically derived scenarios, product development professionals forecasted a higher level of automation in the design process. In literature, this paradigm shift from manual to automated feedback integration is labeled as "cloud-based automated design and additive manufacturing" [7:32079].

D6 - Degree of product novelty: In terms of possible applications of the gathered and processed feedback from digitized products, empirical evidence demonstrated a wide spectrum of possible purposes. In line with Pahl and Beitz [67], D6 refers to the degree of product novelty. Feedback can be harnessed to support new product development (C6.1) or product improvement (C6.2). In the case of new product development, feedback is applied to solve new problems and tasks under consideration of new solution principles [67]. In contrast, feedback can be also be leveraged for the further development of existing devices utilizing the extant solution principles [67]. Product development professionals assessed the strongest impact on optimizing similar products from generation to generation, but also appreciated feedback for entering new terrains.

D7 - Addressed product development stage: During the interviews with different roles from various engineering departments, it became apparent that feedback is applicable in various product development phases. Accordingly, D7 distinguishes the addressed product development stages into product conceptualization (C7.1), product definition (C7.2), and product realization (C7.3), which goes in line with the approved product lifecycle stage model $[2,3,4]$. However, scenarios were not distributed equally, most scenarios referred to the early product conceptualization stage. Industry experts appreciated feedback especially for these early stages as the product definition with the determination of lifecycle implications and costs typically occurs in the very beginning of the product lifecycle [27].

D8 - Enabled business benefit: A pivotal dimension which was inductively derived from the scenarios, is the enabled business benefit for the manufacturers through feedback from the field. In 
line with the established product development framework [27], D8 distinguishes four feedback benefits: First, feedback enables the specification of requirements (C8.1). Second, from a holistic perspective, feedback supports the creation of a customer-centric product portfolio (C8.2). Third, by the aid of feedback, products can be designed for usage overcoming assumption- and experience-based development processes (C8.3). Finally, feedback has the potential to shorten and replace physical prototyping and field testing (C8.4). In terms of enabled business benefits, the scenarios' focus lied on early lifecycle stages.

D9 - Enabled increase in value (neutral): With reference to the manufacturer-independent increase in value, identified scenarios demonstrated various manifestations (D9). In line with the classification by Kiritsis et al. [68], we distinguish technical (C9.1), economic (C9.2), environmental (C9.3), social (C9.4), and combined (C9.5) benefits. Although some empirically derived scenarios clearly address one main increase in value (e.g., economic benefit through optimized selection of purchase components), most scenarios featured combinations (e.g., optimized dimensioning of components resulting in technical, environmental, and social benefits).

\section{Discussion}

With the purpose to illustrate the relevance and usefulness, we discuss the developed taxonomy by the aid of an exemplary scenario. We selected the scenario "Finite element method dimensioning with real loads from the field" which has been in the spotlight in our data collection, but also in practitioners' literature [69] recently. In a nutshell, this scenario describes an activity sequence where environmental and usage loads such as forces and torsional moments are collected from the installed base in order to provide more realistic input for finite element method (FEM) simulations (e.g., structural or thermal analyses). Although these FEM simulations are very accurate from a modeling and computation viewpoint, these approaches suffer from insecure assumptions in terms of input loads. Table 5 illustrates the scenario with the correspondent dimensions and characteristics.

As a matter of principle, the scenario attempts to optimize prospect products predicting the presumable product usage through large-scale data collection with subsequent tailored product design, accordingly the approach to data collection (D1) is proactive. In order to ensure exhaustiveness, product data (D2) from all product instances need to be collected. With discrete sensor data being gathered, their format of appearance (D3) can be characterized as structured. This feedback serves as input for the numerical approximation of differential equations, hence, the scenario's feedback processing complexity (D4) can be described as rather high. To this day, the degree of feedback autonomy has partially automated processing character (D5) as both automated (e.g., data collection and storage) and manual tasks (e.g., CAx design and simulation) are required. The scenario targets the development of future products with a rather small degree of product novelty (D6), namely product improvement of existing products. Furthermore, feedback is utilized in the product development stage (D7) of product definition determining geometries and properties of the component. The obtained business benefit (D8) is optimized design for usage. Finally, the enabled increase in value (D9) is a combination of technical, environmental, and social values.

Table 5. Scenario "Finite element method dimensioning with real loads from the field"

\begin{tabular}{|l|l|l|}
\hline \multicolumn{2}{|l|}{ Dimension } & Characteristic \\
\hline & $\begin{array}{l}\text { D1 - Approach to data } \\
\text { collection }\end{array}$ & $\begin{array}{l}\text { C1.2 - Proactive approach } \\
\text { (ex ante) }\end{array}$ \\
\cline { 2 - 3 } & $\begin{array}{l}\text { D2 - Product data source } \\
\text { (level of abstraction) }\end{array}$ & $\mathrm{C} 2.1$ - Product instance \\
\hline $\begin{array}{l}\text { D3 - Product data source } \\
\text { (format of appearance) }\end{array}$ & $\mathrm{C} 3.1$ - Structured data \\
\hline \multirow{2}{*}{$\begin{array}{l}\text { D4 - Complexity of } \\
\text { feedback processing }\end{array}$} & $\begin{array}{l}\text { C4.3 - High complexity } \\
\text { processing autonomy }\end{array}$ & $\begin{array}{l}\text { C5.2 - Partially automated } \\
\text { feedback processing }\end{array}$ \\
\hline $\begin{array}{l}\text { D6 - Degree of product } \\
\text { novelty }\end{array}$ & $\mathrm{C} 6.2$ - Product improvement \\
\hline $\begin{array}{l}\text { D7 - Addressed product } \\
\text { development stage }\end{array}$ & $\mathrm{C} 7.2$ - Product definition \\
\hline $\begin{array}{l}\text { D8 - Enabled business } \\
\text { benefit }\end{array}$ & $\mathrm{C} 8.3$ - Design for usage \\
\hline $\begin{array}{l}\text { D9 - Enabled increase in } \\
\text { value (neutral) }\end{array}$ & $\mathrm{C} 9.5$ - Combinations \\
\hline
\end{tabular}

\section{Conclusion}

In the course of this paper, the development process of a taxonomy for feedback-driven product development scenarios in manufacturing industries was discussed. Our research was initiated by limited understanding how product usage data can be harnessed for product development although digital technologies created the potential of making the whole product lifecycle visible. Anchored in (1) empirical data and (2) a systematic literature review, our research followed the method for taxonomy development as suggested by Nickerson et al. [12]. Prior literature has acknowledged product usage data notably for maintenance purposes [31,32]. Results reinforce the existence of fruitful potentials for product development objectives as well. Furthermore, results demonstrate the multi-faceted manifestations of feedback-driven product development. Despite these new opportunities, critical issues such as ethic and legal aspects are important to mention which were intensively discussed within the interviews. 
To our knowledge, this study is the first to investigate the role of digital product innovation for product development from a classification model perspective. The developed taxonomy bridges industry specifics and is evaluated in an artificial setting [66]. Following Gregor [70] who puts a taxonomy on a level with a "theory for analysis", our work can be regarded as a "type one theory" enabling analysis and description without a prediction component. In addition, we provide a methodological example how to combine scenario- and classificationbased approaches which may be helpful for other scholars investigating similar phenomena. Beyond, information systems is an inherently interdisciplinary field and thus requires to look into other areas $[45,65]$. With this paper, we link the domain of information systems with product development.

Apriori, we would like to stimulate product developers and decision makers for a more holistic lifecycle thinking. Manufacturers should assess and exploit new opportunities emerging from digital product innovation. The developed taxonomy may act as guiding and structuring, but also creativity fostering element in the vast, but diffuse opportunities that arise from new technological advances. First, the taxonomy helps to understand the different types of feedback-driven product development. Manufacturers can bring transparency in the numerous ideas from their R\&D departments they are confronted with. Second, the taxonomy also supports the playful ideation of so far unknown configurations. Known scenarios can be modified by varying characteristics and new scenarios can be generated by recombining characteristics. Hence, our classification model serves as a foundation to make the right decisions in the competitive market environment of manufacturing industries.

However, there are some important concerns to our research. First, referring to the empirical-toconceptual approach, our research design was qualitative and interpretive. Second, referring to the conceptual-to-empirical approach, our literature review needs to be characterized as non-exhaustive. Given the early stage of research, we cannot guarantee exhaustiveness.

Following the understanding of design as search process $[45,46]$, the taxonomy may be validated in a more naturalistic setting (EVAL4) with consequent iterative adaption of dimensions and characteristics. Additionally, examining feedback-driven product development from technological, economic, and legal viewpoints seem promising avenues for further research. Furthermore, digitized products may be studied in other contexts such as feedback-driven service development. For these tasks, the paper at hand provides first insights and represents a steady starting point.

\section{References}

[1] Nambisan, S., "Information systems as a reference discipline for new product development", MIS Quarterly 27, 1 (2003), pp.1-18.

[2] Terzi, S., Bouras, A., Dutta, D., Garetti, M., and Kiritsis, D., "Product lifecycle management - From its history to its new role", International Journal of Product Lifecycle Management 4, 4 (2010), pp.360-389.

[3] Stark, J., "Product Lifecycle Management: 21st Century Paradigm for Product Realisation", Springer, London, 2015.

[4] Kiritsis, D., "Closed-loop PLM for intelligent products in the era of the Internet of things", Computer-Aided Design 43, 5 (2011), pp.479-501.

[5] Parlikad, A.K., McFarlane, D., Fleisch, E., and Gross, S., "The Role of Product Identity in End-of-Life Decision Making", University of Cambridge, Cambridge, United Kingdom, 2003.

[6] Heisig, P., Caldwell, N.H.M., Grebici, K., and Clarkson, P.J., "Exploring knowledge and information needs in engineering from the past and for the future - results from a survey", Design Studies 31, 5 (2010), pp.499-532.

[7] Lehmhus, D., Wuest, T., Wellsandt, S., Bosse, S., Kaihara, T., Thoben, K.-D., and Busse, M., "Cloud-Based Automated Design and Additive Manufacturing: A Usage Data-Enabled Paradigm Shift", Sensors 15, 12 (2015), pp.32079-32122.

[8] Yoo, Y., "Computing in everyday life: a call for research on experiential computing”, MIS Quarterly 34, 2 (2010), pp.213-231.

[9] Yoo, Y., Henfridsson, O., and Lyytinen, K., "Research Commentary: The New Organizing Logic of Digital Innovation: An Agenda for Information Systems Research", Information Systems Research 21, 4 (2010), pp.724-735.

[10] Yoo, Y., Boland, R.J., Lyytinen, K., and Majchrzak, A., "Organizing for Innovation in the Digitized World", Organization Science 23, 5 (2012), pp.1398-1408.

[11] Oliver Wyman, "The Internet of Things - Disrupting traditional Business Models", Oliver Wyman, 2015.

[12] Nickerson, R.C., Varshney, U., and Muntermann, J., "A method for taxonomy development and its application in information systems", European Journal of Information Systems 22, 3 (2013), pp.336-359.

[13] Nambisan, S., "Information Technology and Product/Service Innovation: A Brief Assessment and Some Suggestions for Future Research", Journal of the Association for Information Systems 14, 4 (2013), pp.215-226.

[14] Leonardi, P.M., and Barley, S.R., "Materiality and Change: Challenges to Building Better Theory About Technology and Organizing", Information and Organization 18, 3 (2008), pp.159176.

[15] Lee, E.A., "Cyber-Physical Systems: Design Challenges", Proceedings of the 11th International Symposium on Object Oriented Real-Time Distributed Computing (2008), Orlando, Florida.

[16] Park, K.-J., Zheng, R., and Liu, X., "Cyber-physical systems: Milestones and research challenges", Computer Communications 36, 1 (2012), pp.1-7.

[17] Meyer, G.G., Främling, K., and Holmström, J., "Intelligent Products: a survey", Computers in Industry 60, 3 (2009), pp.137148.

[18] Lopez, T.S., Ranasinghe, D.C., Patkai, B., and McFarlane, D., "Taxonomy, Technology and Applications of Smart Objects", Information Systems Frontiers 13, 2 (2011), pp.281-300.

[19] Kortuem, G., Kawsar, F., Fitton, D., and Sundramoorthy, V., "Smart Objects as Building Blocks for the Internet of Things", IEEE Internet Computing 14, 1 (2010), pp.44-51.

[20] Porter, M.E., and Heppelmann, J.E., "How Smart, Connected Products Are Transforming Competition", Harvard Business Review 92, 11 (2014), pp.64-86.

[21] Whitmore, A., Agarwal, A., and Xu, L.D., "The Internet of Things - A survey of topics and trends", Information Systems Frontiers 17, 2 (2015), pp.261-274.

[22] Atzori, L., Iera, A., and Morabito, G., "The Internet of Things: A survey", Computer Networks 54, 15 (2010), pp.2787-2805.

[23] Novales, A., Mocker, M., and Simonovich, D., "IT-enriched "Digitized" Products: Building Blocks and Challenges", Proceedings of the 22nd Americas Conference on Information Systems (2016), San Diego, California. 
[24] Herterich, M., Eck, A., and Uebernickel, F., "Exploring how Digitized Products enable Industrial Service Innovation - An Affordance Perspective", Proceedings of the 24th European Conference on Information Systems (2016), Istanbul, Turkey.

[25] Andreasen, M.M., and Hein, L., "Integrated Product Development", IFS Publications, Bedford, 1987.

[26] Ulrich, K.T., and Eppinger, S.D., "Product Design and Development", McGraw-Hill, Boston, 2008.

[27] Eigner, M., and Roubanov, D., "Modellbasierte virtuelle Produktentwicklung", Springer, Berlin/Heidelberg, 2014.

[28] Jun, H.-B., and Kiritsis, D., "Several Aspects of Information Flows in PLM", Proceedings of the 9th IFIP WG 5.1 International Conference on PLM (2012), Montreal, Canada.

[29] Wellsandt, S., Hribernik, K., and Thoben, K.-D., "Content analysis of product usage information from embedded sensors and web 2.0 sources", Proceedings of the 21 st ICE/IEEE International Technology Management Conference (2015), Belfast, Ireland.

[30] Wellsandt, S., Hribernik, K., and Thoben, K.-D., "Sources and Characteristics of Information about Product Use", Procedia CIRP 36 (2015), pp.242-247.

[31] Shin, J.-H., Kiritsis, D., and Xirouchakis, P., "Design modification supporting method based on product usage data in closed-loop PLM", International Journal of Computer Integrated Manufacturing 28, 6 (2014), pp.551-568.

[32] Shin, J.-H., Jun, H.-B., Kiritsis, D., and Xirouchakis, P., "Function performance evaluation and its application for design modification based on product usage data", International Journal of Product Lifecycle Management 4, 1/2/3 (2009), pp.84-113.

[33] Chen, H., Chiang, R.H.L., and Storey, V.C., "Business Intelligence and Analytics: From Big Data to Big Impact", MIS Quarterly 36, 4 (2012), pp.1165-1188.

[34] Chen, C.L.P., and Zhang, C.-Y., "Data-intensive applications, challenges, techniques and technologies: A survey on Big Data", Information Sciences 275 (2014), pp.314-347.

[35] Li, J., Tao, F., Cheng, Y., and Zhao, L., "Big Data in product lifecycle management", The International Journal of Advanced Manufacturing Technology 81, 1 (2015), pp.667-684.

[36] Cito, J., Leitner, P., Fritz, T., and Gall, H., "The Making of Cloud Applications - An Empirical Study on Software Development for the Cloud", Proceedings of the 10th Joint Meeting on Foundations of Software Engineering (2010), Bergamo, Italy.

[37] Herterich, M., Buehnen, T., Uebernickel, F., and Brenner, W., "A Taxonomy of Industrial Service Systems Enabled by Digital Product Innovation", Proceedings of the 49th Hawaii International Conference on System Sciences (2016), Kauai, Hawaii.

[38] Perera, C., Zaslavsky, A., Christen, P., and Georgakopoulos, D., "Context Aware Computing for The Internet of Things: A Survey", IEEE Communications Surveys \& Tutorials 16, 1 (2014), pp.414-454.

[39] March, S.T, and Smith, G.F., "Design and natural science research on information technology", Decision Support Systems 15 (1995), pp.251-266.

[40] Bailey, K.D., "Typologies and Taxonomies: An Introduction to Classification Techniques", Sage, Thousand Oaks, 1994.

[41] Nickerson, R.C., Varshney, U., Muntermann, J., and Isaac, H., "Taxonomy Development in Information Systems: Developing a Taxonomy of Mobile Applications", Proceedings of the 17th European Conference on Information Systems (2009), Verona, Italy.

[42] Pinder, C.C., and Moore, L.F., "The Resurrection of Taxonomy to Aid the Development of Middle Range Theories of Organizational Behavior", Administrative Science Quarterly, 24, 1 (1979), pp.99-118.

[43] Carper, W.B., and Snizek, W.E., "The Nature and Types of Organizational Taxonomies: An Overview", Academy of Management Review, 5, 1 (1980), pp.65-75.

[44] Doty, D.H., and Glick, W.H., "Typologies as a Unique Form of Theory Building: Towards Improved Understanding and Modeling", Academy of Management Review, 19, 2 (1994), pp. 230-251.

[45] Hevner, A.R., March, S.T., Park, J., and Ram, S., "Design Science in IS Research", MIS Quarterly 28, 1 (2004), pp.75-105.

[46] Peffers, K., Tuunanen, T., Rothenberger, M.A., and Chatterjee, S., "A Design Science Research Methodology for Information Systems Research", Journal of Management Information Systems 24, 3 (2008), pp.45-77.
[47] Carroll, J.M., "Scenario-based design: Envisioning work and technology in system development", John Wiley \& Sons, New York, 1995.

[48] Carroll, J.M., "Five Reasons For Scenario-based Design", Proceedings of the 32nd Hawaii International Conference on System Sciences (1999), Maui, Hawaii.

[49] Alexander, I., and Neil, M., "Scenarios, Stories, Use Cases: Through the Systems Development Life-Cycle", John Wiley \& Sons, Chichester, England, 2004

[50] Fathi, M., Abramovici, M., Holland, A., Lindner, A., and Dienst, S., "Nutzungs-Szenarien eines wissensbasierten Assistenzsystems zur Entscheidungsunterstützung in der Produktverbesserung", Proceedings of the 6th Conference on Professional Knowledge Management (2011), Innsbruck, Austria.

[51] Kanungo, S., and Vikas, J., "General Systems Theory: A Guiding Framework for IS Research", Proceedings of the 13th Americas Conference on Information Systems (2007), Keystone, Colorado.

[52] Checkland, P., "Systems Thinking, Systems Practice", John Wiley \& Sons, Chichester, England, 1981.

[53] Yin, R.K., "Case Study Research - Design and Methods", Sage, London, 2009

[54] Eisenhardt, K.M., "Building Theories from Case Study Research", Academy of Management Review 14, 4 (1989), pp.532-550.

[55] Morgan, D.L., "Focus Groups as Qualitative Research", Sage, Newbury Park, 1988.

[56] Lincoln, Y.S., and Guba, E.G., "Fourth Generation Evaluation", Sage, Newbury Park, 1989.

[57] Coyne, I.T., "Sampling in qualitative research. Purposeful and theoretical sampling; merging or clear boundaries?", Journal of Advanced Nursing, 26 (1997), pp.623-630.

[58] Olhager, J., "Strategic positioning of the order penetration point", International Journal of Production Economics, 85, 3 (2003), pp.319-329.

[59] Schultze, U., and Avital, M., "Designing Interviews to Generate Rich Data for Information Systems Research", Information and Organization 21, 1 (2011), pp.1-16.

[60] Alam, I., "Fieldwork and Data Collection in Qualitative Marketing Research", Qualitative Market Research: An International Journal 8, 1 (2005), pp.97-112.

[61] Sinkovics, R., Penz, E., and Ghauri, P.N., "Analysing Textual Data in International Marketing Research", Qualitative Market Research: An International Journal 8, 1 (2005), pp.9-38.

[62] Nielsen, J., "The Use and Misuse of Focus Groups", IEEE Software 14, 1 (1997), pp.94-95.

[63] Vom Brocke, J., Simons, A., Niehaves, B., Riemer, K., and Cleven, A., "Reconstructing the giant: On the importance of rigour in documenting the literature search process", Proceedings of the 17th European Conference on Information Systems (2009), Verona, Italy.

[64] Cooper, H.M., "Organizing Knowledge Syntheses: A Taxonomy of Literature Reviews", Knowledge in Society 1 (1988), pp.104-126.

[65] Webster, J., and Watson, R., "Analyzing the past to prepare the future: Writing a literature review", MIS Quarterly 26, 2 (2002), pp.xiii-Xxiii.

[66] Sonnenberg, C., and vom Brocke J., "Evaluations in the Science of the Artificial - Reconsidering the Build-Evaluate Pattern in Design Science Research", in Peffers, K., Rothenberger, M., and Kuechler, B. (eds.), "Design Science Research in Information Systems. Advances in Theory and Practice", Springer, Berlin/Heidelberg, 2012, pp.381-397.

[67] Pahl, G., and Beitz, W., "Konstruktionslehre - Grundlagen erfolgreicher Produktentwicklung - Methoden und Anwendung", Springer, Berlin/Heidelberg, 2007.

[68] Kiritsis, D., Bufardi, A., and Xirouchakis, P., "Research issues on product lifecycle management and information tracking using smart embedded systems", Advanced Engineering Informatics 17, 3/4 (2003), pp.189-202.

[69] Wasserman, S., "GE and ANSYS Team Up to Bring IoT Data into Simulations", URL: www.engineering.com/DesignSoftware/ DesignSoftwareArticles/ArticleID/10756, accessed: 2016/04/10

[70] Gregor, S., "The Nature of Theory in Information Systems", MIS Quarterly 30, 3 (2006), pp.611-642. 